\title{
METHODOLOGY OF SELECTION OF HEAVY AND OVERSIZED FREIGHT TRANSPORTATION SYSTEM
}

\author{
Artūras Petraška ${ }^{1}$, Kristina Čižiūnienè $\dot{e}^{2}$, Olegas Prentkovskis ${ }^{3}$, Aldona Jarašūnienè $^{4}$ \\ 1, 2, 4 Department of Logistics and Transport Management, \\ Vilnius Gediminas Technical University \\ Plytinés g. 27, LT-10105, Vilnius, Lithuania \\ ${ }^{1}$ arturas.petraska@vgtu.lt; ${ }^{2}$ kristina.ciziuniene@vgtu.lt; ${ }^{4}$ aldona.jarasuniene@vgtu.lt \\ ${ }^{3}$ Department of Mobile Machinery and Railway Transport, \\ Vilnius Gediminas Technical University, \\ Plytinés g. 27, LT-10105, Vilnius, Lithuania \\ 3 olegas.prentkovskis@vgtu.lt
}

\begin{abstract}
Dynamically changing economic conditions influence the growing demand of various freights transportation. Inevitably, the demand for heavy and oversized freight transportation is increasing, which is quite problematic. In many cases, it is very difficult to standardize the technology of heavy and oversized freight transportation. Decisions are necessary, which would allow to deliver heavy or oversized freight to the destination place, allocating fewer funds as possible for infrastructure improvements, choosing the most appropriate mode of transport for such freight transportation or using advantages of multimodal (combined) transport. In this article there will be selected methodology of heavy and oversized freight transportation system, carrying heavy and oversized freight by road transport. There will also be made an approval of this methodology, based on a hypothetical route within Lithuanian territory.
\end{abstract}

Keywords: heavy and oversized freight, transportation system, road, selection methodology

\section{Introduction}

The growing demand of various freights transportation is influenced by increasing countries economic development, dynamically changing economic conditions. Building large economic facilities such as a large thermal, nuclear or wind power plants, oil refineries and chemical plants will inevitably provoke a demand of heavy and oversized freight (hereafter - HOF) transportation, which is quite problematic. Given the fact that the HOF can be transported by more than one mode of transport, it can be said that the proper freight transportation route selection is a complex, multifunctional task (Xu and Hoel, 2001; Wang et al., 2011; Petraška and Palšaitis, 2011, 2012; Bazaras et al., 2013; Petraška et al., 2017; Newnam et al., 2017; Palšaitis and Petraška, 2012; Pronello et al., 2017; Sánchez-Díaz, 2017; Andrés and Padilla, 2015; Li et al., 2014). Road transport is one of the most complicated modes of transport, and demanding most technological solutions (Sivilevičius, 2011; Podvezko and Sivilevičius, 2013; ElRashidy and Grant-Muller, 2016; Carrara and Longden, 2017).

Purpose of this article is to create the methodology to select a system of HOF transportation by road transport.

There are following tasks to achieve the purpose:

- to perform the analysis of theoretical aspects concerning transport routing, when carrying HOF;

- to create HOF transportation methodology, after evaluating the routing principles;

- to perform hypothetical inspection of created methodology applicability using an example of Lithuania.

The paper comprises five sections, the first one being the introduction, followed by Section 2 that is dedicated to relevant literature review about theoretical aspects of transportation routing, in case of transportation of heavy or oversized freight by road transport. Section 3 presents data collection about evaluation of $\mathrm{HOF}$ transport routing principles and new methodology of universal system for $\mathrm{HOF}$ routing creation. Results and Discussion about application example of universal system for HOF routing by road transport are given in Section 4. Finally, the 5 Section presents the Conclusion. 


\section{Theoretical Formulation of the Problem}

Durham and Faghri (2002) in their analyses investigate the capabilities using Geographic Information System (GIS) to estimate potential transportation routes of HOF. However, these systems are not always allow to assess what is the turning radius of the oversized vehicle, which can be critical and may limit the movement of the vehicle on a regular road network (Sarker et al., 2012) and other specific elements. On the other hand, it is very important that oversized vehicle remains undeviating from the planned transportation route, chosen by evaluating the vehicle's dimensions together with the load, weight and other characteristics, in order to ensure traffic safety and to prevent damage to the road infrastructure (ECMT, 2006; Vaitkus et al., 2016; Kombe et al., 2017; Dell'Acqua et al., 2016; UšpalytéVitkūnienè and Laureshyn, 2017; Pauer, 2017).

Using GIS software aims to find the shortest route in the existing road network taking into account the vehicle's height and weight for each road segment/section (Datla et al., 2004). Thus, during the analysis of the entire road network, based on oversized vehicle parameters, those roads, which do not meet the vehicle parameters, are eliminated. During the analysis of the road network, it is appropriate to assess the improvement possibilities of "bottlenecks" or restrictive elements of HOF transportation. In this case GIS system would become inaccurate (Durham and Faghri 2002).

Many researchers (Hall et al., 2007; Sousa et al., 2016; Abulizi et al., 2016; Gardziejczyk and Zabicki, 2017; Doumiati et al., 2014; Sivilevičius et al., 2017; Bartuška et al., 2016; Sivilevičius and Škevičius 2006) examine in their works a road plan, curves marking methods, longitudinal road profile, bank, they provide a methodology for selecting the pavement structure, there are presented calculations of the road plan and longitudinal profile elements, of the designed Annual Average Daily Traffic Intensity $\left(A A D T I_{d}\right)$, of bank, of earthwork volumes. Given the fact that roads in most countries are divided into categories, the designed road category is determined by the designed Annual Average Daily Traffic Intensity. For example, in Lithuania, the determination of road category comprises the 20-year long-term period.

HOF transportation conditions, compared with the standard freight transportation are different, but the principles of the classification of road sections according to the traffic intensity are similar, so the traffic intensity assessment is an important factor in the planning of the sections of HOF transportation routes in different areas.

During the planning of HOF transportation route, it is necessary to evaluate the existing obstacles on the ground surface, which may need to overtake during the transportation process (Petraška and Palšaitis, 2012; Bazaras et al., 2013; Petraška et al. 2017; Palšaitis and Petraška, 2012; et al. 2017; Benekos and Diamantidis 2017; Conca et al. 2016).

The road is designed taking into account technical and economic calculations, which are based on road economic necessity and expedience expediency (Armstrong and Taylor, 2000; Park, 2000; Iwański et al., 2016; Van Damme et al., 2016; Bickel et al., 2006). One of the most important documents, according to which issues concerning road design and construction expediency, their sequence and volume of works are dealt, it is the road development scheme. Preparing this scheme, there are following actions: formation of region characteristic, network paths analysis, calculation of transported freight and passengers dimension and traffic intensity on network roads, presentation of proposals to develop the road network, description of natural conditions in the road construction area, determination of capital investment efficiency, presentation of road technical and economic characteristics, presentation of conclusions describing the road network compliance with current and prospective traffic, presentation of recommendations for road network configuration development and for road category increase. Designing the new road construction, economic research is carried out. One of the most important signs of economic research in the area are focus points of freight and passenger, which determine the volume of freight transported [42]. Therefore, an important factor is the assessment of necessary elements, which allows properly selecting the transportation route.

\section{Data Collection and Creation of Methodology}

\subsection{Evaluation of HOF Transport Routing Principles}

Having the necessity to carry HOF, there are different conditions to define that must be met, that the transport process would be successful. The conditions determining the appearance of that demand may be twofold: it is a specific demand for transporting specific freight from point A to point $\mathrm{B}$, or forecast that it will appear a multiple demand to carry such freight within a certain territory. 
The examination of the HOF transportation process starting from the selection of route, mode of transport and transportation vehicle and ending with transportation action planning and implementation, it can be seen that the individual transportation process parts and operations in different modes of transport has obvious qualitative similarities, but can vary depending on the implementation cost or time (for example, road sections, not meeting the requirements of HOF transportation, the demand to improve the road surface or to deepen inland waterway watercourse, to increase road, railway or waterway turning radius etc.). The financial costs and time spent will be needed to carry out all the necessary works. The most rational transportation route is that, which will incur the minimum financial and time costs. It is appropriate to classify systematically whole reasons determining the above factors, by spotlighting repetitive route sections attributing the adequate criterion weights. After formalizing the entire HOF route evaluation process, it appears a possibility to objectively compare different routes and different modes of transport by the same scoring system and to found the most acceptable transportation option.

\subsection{Creation of New Methodology} criteria.

In order to ensure proper transportation of the HOF, it is proposed to evaluate the following

1. Restrictions on the physical characteristics of the road - this group includes two criteria relate to the following:

1.1 Road section pavement. Influence of road section pavement to freight transportation speed - this criterion is designed to compare the route advantages for the different modes of transport. In case of road route assessment, there are distinguished two alternatives of road section criterion: asphalt or gravel. These options allow the assessment of freight movement speed on the route. Option of the lack of road section allows evaluating the possibility of a new road construction or searching for other alternatives.

Index " $A$ " in formulas means sort of road transport. Influence of road section pavement to transport speed:

$$
S_{A D}=x_{A 1} \cdot k_{A D}+x_{A 2} \cdot k_{A Z},
$$

whereas: $S_{A D}$ - total duration of HOF transportation by road on route (in months); $x_{A I}-$ length of road with asphalt pavement (in $\mathrm{km}$ ); $x_{A 2}$ - length of road with gravel pavement (in $\mathrm{km}) ; k_{A D}$ - coefficient - the inverse rate to the average freight transportation speed on asphalt pavement; $k_{A Z}$ - coefficient - the inverse rate to the average freight transportation speed on gravel pavement;

$$
\begin{aligned}
& k_{i j} \in\left(\begin{array}{c}
x_{A 1} \\
x_{A 2}
\end{array}\right), x_{A 1}=[0, \ldots, n], x_{A 2}=[0, \ldots, n] \\
& k_{i j}=\frac{1}{b \cdot v_{\text {aver }}} \cdot \alpha \cdot \gamma,
\end{aligned}
$$

whereas: $k_{i j}$ - a road pavement evaluation criterion numeric value in the analysed transport category; $b$ - number of hours per month ( $b=720$ hours, it is assumed that month consist of 30 days); $v_{\text {aver }}$ - average speed of HOF transportation in the analysed transport category; $\alpha$-route longevity (in years); $\gamma$ - HOF transportation frequency per year; $n$ - the number of road sections with different road pavements.

Sizes $\alpha$ and $\gamma$ gain influence on the result with the values, if the HOF transportation route is long-term. In case of a single transportation, these values practically have no influence to result.

1.2 The physical quality of the road pavement at the assessment moment. Physical road pavement quality at the assessment moment - this criterion allows evaluating the road pavement for freight transportation and the demand for one or the other action to ensure the required quality of the road. For the road, the total value of the financial costs, ensuring the required quality of the road pavement for HOF transportation is assessed according to formula (4). The value of financial costs is assessed by Relative Financial Units (hereafter RFU), which concrete value depends on the economic-financial environment of examined territory: 
$F_{A Q}=x_{A F 1} \cdot k_{A F 1}+x_{A F 2} \cdot k_{A F 2}+x_{A F 3} \cdot k_{A F 3}$,

whereas: $F_{A Q}$ - total value of the financial costs required for the route improvement for $\mathrm{HOF}$ transportation by road transport (in RFU); $x_{A F 1}$ - number of road sections of $100 \mathrm{~m}$, requiring minor improvements (in pcs.); $x_{A F 2}$ - number of road sections of $100 \mathrm{~m}$, requiring major works (in pcs.); $x_{A F 3}$ - number of road sections of $100 \mathrm{~m}$, requiring new road construction (in pcs.); $k_{A F 1}$ - coefficient - dimension, meaning the average financial costs of small improvements to make on the route (in RFU); $k_{A F 2}$ - coefficient - dimension, meaning the average financial costs of road improvement major works (in RFU); $k_{A F 3}-$ coefficient - dimension, meaning the average financial costs of arranging a new road section (in RFU).

$k_{F i j}$ - dimension, which means the financial costs incurred in preparing route for HOF transportation, when it is necessary to remove small obstacles. The coefficient value depends on rates of route improvement operations and work standards existing on a specific area.

$k_{F i j} \in \begin{cases}c, & c=[0, \ldots, n], \\ z, & \mathrm{z}=[0, \ldots, n], \\ g, & g=[0, \ldots, n],\end{cases}$

whereas: $c$ - size assessing financial costs of road structures destruction and rebuild (in RFU); $z$ - size assessing financial losses resulting from time spent destructing or rebuilding the road structures, and the costs for the time spent in the necessary legal procedures (in RFU); $g$ - financial cost value of necessary to carry out additional works (in RFU); $n-$ number of critical points, where improvements must be carried out (in pcs.).

During calculation of real value of quality criterion of physical road pavement, it is used indicator $d$ of possible financial loss. This is value estimating possible financial loss per unit of time, related to the loss of time in accomplishing the necessary procedures (for example, designing, planning, receiving of permits etc.). This indicator is measured in money terms. The rate of this indicator depends on the policy of banks, interest rates and labour force rates in the analysed area.

$d=\frac{E_{c} \cdot P_{b}}{12}+U_{w}$

whereas: $d$-value of possible financial costs (losses) (in RFU); $E_{c}$ - annual amount of credit for implementation of HOF transportation project (in RFU); $P_{b}$ - bank annual interest rate (in \%); $U_{d}$ - monthly wage of staff involved in the project implementation process (in RFU).

Obstacles due to road section geometry - to describe this criterion, the best example is the freight corridor term that defines a freight transportation height, width and curvature parameters. Further there are examined aspects of this criterion for each of mentioned characteristics.

2. Road turning radius of curvature. In both road and inland waterway routes assessment cases, the criterion has three alternatives: the curvature radius corresponds to the conditions of freight transportation; there are necessary minor improvements of route - which means minor works of straightening road radius, minor widening of road embankment etc.; major works would mean a substantial reorganization of the road section.

- Small radius road turnings. The total value financial costs $\left(F_{A S}\right)$ in route of HOF transportation by road transport, needed to increase the radius of curvature, is defined as follows:

$$
F_{A S}=x_{A S 1} \cdot k_{A S 1}+x_{A S 2} \cdot k_{A S 2},
$$

whereas: $x_{A S 1}$ - number of small improvements on the road route, in order to ensure the required turning radius (in pcs.); $x_{A S 2}$ - number of sections of the road route, in which major works must be carried out to ensure the required turning radius (in pcs.); $k_{A S 1}$ - value corresponding to the average financial costs necessary for small improvements of road 
turning radius on a route (in RFU); $k_{A S 2}$ - value corresponding to the average financial costs necessary for major improvements of road turning radius on a route (in RFU).

The weight of criterion evaluating the radius improvement of the road turning curvature is equivalent to construction of $100 \mathrm{~m}$ of new road. The demand to change road curvature radius occurs depending on the technical capabilities of the vehicle to turn within a certain radius. These works are attributed to the major works category.

Evaluation of minor works ensuring proper road curvature radius, road corridor width or quality:

- Destruction of road structures (minor works) includes destruction and rebuild of kerbs, road signs and hedges.

- Road processing in order to reduce the potential negative impact on the road pavement. An example could be the processing of road pavement using dolomite chippings.

- $\quad$ Grading - temporary pavement improvement, for temporary route.

$$
K_{\text {grading }}=k_{g r}+\left(t_{g r} \cdot d\right) \text {, }
$$

whereas: $K_{\text {grading }}$ - numeric value of criterion "road grading"; $k_{g r}$ - financial expenses of $100 \mathrm{~m}$ road grading (in RFU); $t_{g r}$ - road grading time (in months); $d$-value of possible financial costs (losses) (in RFU).

- Road graveling - temporary road pavement improvement.

$$
K_{\text {graveling }}=k_{\text {grv }}+\left(t_{\text {grv }} \cdot d\right) \text {, }
$$

whereas: $K_{\text {graveling }}$ - numeric value of road graveling coefficient; $k_{g r v}$ - financial expenses of $100 \mathrm{~m}$ road graveling (in RFU); $t_{g r v}$ - time required to perform graveling works on route (in months); $d$ - value of possible financial costs (losses) (in RFU).

3. Transportation corridor on road section is too narrow. Freight transportation corridor on road section is too narrow - assessing road route, criterion consists of four alternatives: the corridor width corresponds to the freight transportation conditions; there are necessary minor routing improvements - which means minor works of road widening, a minor road embankment widening etc.; major works would mean essential reorganization of the road section; a version that the problem cannot be solved rationally, means that it is necessary to select another transportation alternative.

$$
F_{A K S}=x_{A K S 1} \cdot k_{A K S 1}+x_{A K S 2} \cdot k_{A K S 2}+x_{A K S 3} \cdot k_{A K S 3} \text {, }
$$

whereas: $F_{A K S}$ - the total value of the financial costs required for $\mathrm{HOF}$ carried by road, corridor width increase (in RFU); $x_{A K S 1}$ - number of minor improvements on the road route, ensuring the required transportation corridor width (in pcs.); $x_{A K S 2}-$ number of road sections on the route, where it is necessary to carry out major works, ensuring the required transportation corridor width (in pcs.); $x_{A K S 3}$ - number of impassable sections of road route due to too low width of transportation corridor (in pcs.); $k_{A K S 1}$ - value, meaning the average financial costs for road corridor widening minor improvements to make on the route (in RFU); $k_{A K S 2}$ - value, meaning the average financial costs for road corridor widening major works to make on the route (in RFU); $k_{A K S 3}$ - value, equal to the infinity. It means that when critical area (such as curve, bridge, throughputs, etc.) appears on the road route, which cannot be removed, bypassed, rebuilt or otherwise avoided, in such a case the freight transportation capability on this route is not analysed.

4. Barriers due to bridges/dams along the route. Insufficient bridge carrying capacity - this criterion has five senses: the bridge carrying capacity meets the conditions of freight transportation (in this case the criterion weighting value is equal to 0); there is required a metal ramp or bridge reinforcement; it is necessary to install a throughput; there is required a new bridge construction; it is impossible to rationally solve the problem - it is necessary to use other mode of transport.

$$
F_{A T}=x_{A T 1} \cdot k_{A T 1}+x_{A T 2} \cdot k_{A T 2}+x_{A T 3} \cdot k_{A T 3}+x_{A T 4} \cdot k_{A T 4},
$$

whereas: $F_{A T}$ - total value of the financial costs for HOF transportation via bridges or throughputs along the route to ensure the conditions (in RFU); $x_{A T 1}-$ number of places along 
the road route, where it is appropriate to install a metal ramp ensuring safe HOF movement through the bridges or throughputs along the route (in pcs.); $x_{A T 2}$ - number of new throughputs along the road route (in pcs.); $x_{A T 3}$ - number of bridges necessary to newly build along the road route (in pcs.); $x_{A T 4}$ - number of impassable sections along the road route (in pcs.); $k_{A T 1}-$ value, meaning the average financial costs of installing/dismantling the metal ramp (in RFU); $k_{A T 2}-$ size, meaning the average financial costs of installing throughput on the route (in RFU); $k_{A T 3}-$ value, meaning the average financial costs of building a new bridge on the road route (in RFU); $k_{A T 4}-$ value, equal to the infinity. It means that when critical area appears on the road route due to insufficient carrying capacity of bridge or throughput, which cannot be removed, bypassed, rebuilt or otherwise avoided, in such a case the freight transportation possibility on this route is not analysed.

- Construction of throughput - value of this criterion weight is calculated considering throughput design and construction time and value of bypass road construction:

$$
K_{t h}=k_{k}+\left(t_{c} \cdot d\right)+\left(l_{t h} \cdot a_{t h} \cdot k_{t h}\right)+\left(t_{t h} \cdot d\right),
$$

whereas: $K_{t h}$ - numeric value of criterion "construction of throughput" (in RFU); $k_{k}$ construction cost of one kilometre of road (in RFU); $t_{c}$ - road/object construction time (in months); $d$ - value of possible financial costs (losses) (in RFU); $l_{t h}-$ length of constructed throughput (in meters); $a_{t h}$ - width of constructed throughput (in meters); $k_{t h}-$ cost of one square meter throughput construction (in RFU); $t_{t h}$ - throughput construction time (in months).

- Metal ramp - this is a temporary tool of route application for HOFs transportation. This is metal construction, covering too weak small bridges or throughputs. In that case, the ramp helps to ensure the necessary carrying capacity of structure. Ramp's mounting is related to the necessity of bypass road construction. This measure is applied only for road routes adaptation for the HOF transportation.

With the possibility of using metal ramp, numeric value of criterion can be calculated as follows:

$$
K_{\text {ramp }}=\left(t_{R} \cdot d\right)+K_{n r}
$$

whereas: $K_{\text {ramp }}$ - numeric value of criterion "required metal ramp", (in RFU); $t_{R}-$ ramp installation time (in months); $d$-value of possible financial costs (losses) (in RFU); $K_{n r}-$ construction of new local road (in RFU).

- Numeric value of $K_{\text {ramp }}$ on road transport depends on the ramp's acquisition/delivery time $t_{1}$, construction/installation time $t_{2 \text { ramp }}$.

$t_{R}=t_{1}+t_{2 \text { ramp }}$,

whereas: $t_{R}$ - total ramp installation time (in months); $t_{1}$ - ramp's acquisition/delivery time (in months); $t_{2 \text { ramp }}$ - ramp assembly/disassembly time (in months).

The numerical value of the criterion "construction of a new bridge" is calculated according to the formula:

$$
K_{T}=\left(l_{T} \cdot a_{T} \cdot k_{T}\right)+\left(t_{T} \cdot d\right),
$$

5. Total length of the route - this criterion belongs to the evaluation category of consistently changing factors. The route length is assessed in kilometres. Weights of this criterion of different transport modes are different because of different freight transportation speed and transportation price per kilometre.

$$
F_{\Sigma L}=\sum l_{i} c_{i k m}
$$

whereas: $F_{\Sigma L}$ - total HOF transportation cost in case of multimodal (combined) transportation (in RFU); $l_{i}$ - distance of HOF transportation by $i$-th mode of transport (in $\mathrm{km}$ ); $c_{i k m}-\mathrm{HOF}$ transportation price per $1 \mathrm{~km}$ by $i$-th mode of transport (in RFU).

The weight of criterion evaluating total route length is assessed regarding to HOF transportation time and costs due to social factors.

$$
K_{\text {length }}=t_{K} \cdot d \text {, }
$$


whereas: $K_{\text {length }}-$ numeric value of total route length criterion (in RFU); $t_{K}$ - planned freight transportation time (in months); $d$-value of possible financial costs (losses) (in RFU).

6. Demand for installation of transhipment sites. When transporting HOF by vehicles, the value of total costs required for such transhipment site installation, is calculated as follows:

$F_{A P}=x_{A P 1} \cdot k_{A P 1}$,

whereas: $F_{A P}$ - installation costs of transhipment site on road route (in RFU); $x_{A P 1}$ - number of HOF transhipment sites to another mode of transport required to be installed along the road route (in pcs.); $k_{A P 1}$ - value, meaning the average financial costs required to HOF transhipment site to another mode of transport along the road route (in RFU).

There are following criteria evaluating the demand of transshipment site and freight storage area installation:

- Transhipment site - this may be a temporary freight unloading from one mode of transport to another area or temporary pier.

$$
K_{\text {tranship }}=t_{t r} \cdot d+k_{t r} \text {, }
$$

whereas: $K_{\text {tranship }}$ - numeric value of criterion "transhipment site demand" (in RFU); $t_{t r}-$ transhipment site installation time (in months); $k_{t r}$ - transhipment site installation cost (in $\mathrm{RFU}) ; d$ - value of possible financial costs (losses) (in RFU).

7. Demand of freight storage areas installation. The storage areas' installation costs along the road route are evaluated as follows:

$F_{A Y}=x_{A Y 1} \cdot k_{A Y 1}$,

whereas: $F_{A Y}$ - costs of storage area installation along the road route (in RFU); $x_{A Y 1}$ - number of the HOF storage areas, required to install along the road route (in pcs.); $k_{A Y 1}$ - value, meaning the average financial costs installing HOF storage area along the road route (in RFU).

8. Obstacles due to the legal (including environmental) requirements. Assessing the road route, the criterion has following alternatives: the demand of passage through towns/villages - this criterion is related to the oversized and heavy freight transportation rules through the major urban areas, or to the needs concerning route improvement on those areas; demand of protected areas' passage means the evaluation of obstacles appearing a demand of route development in those areas.

$$
F_{A J}=x_{A J 1} \cdot k_{A J 1}+x_{A J 2} \cdot k_{A J 2}+x_{A J 3} \cdot k_{A J 3}+x_{A J 4} \cdot k_{A J 4} \text {, }
$$

whereas: $F_{A J}$ - total costs incurred in removing the obstacles due to the legal restrictions on road route (in RFU); $x_{A J 1}$ - number of towns / settlements along the road route (in pcs.); $x_{A J 2}-$ number of protected areas along the route (in pcs.); $x_{A J 3}$ - number of permits required to install transhipment site along the road route (in pcs.); $x_{A J 4}$ - number of permits required to install a temporary HOF storage area along the road route (in pcs.); $k_{A J 1}$ - coefficient to compensate costs for social losses (in RFU); $k_{A J 2}$ - factor between price obtaining a permit and time spent (in RFU); $k_{A J 3}$ - cost coefficient for obtaining a permit to install a transhipment site (in RFU); $k_{A J 4}-$ cost factor for obtaining a permit to install a temporary storage area (in RFU).

9. Time losses due to the traditional transport intensity on analysed section of the road - this criterion has three common alternatives to all the modes of transport and thus has the an objective to assess the social consequences of oversized and heavy freight transportation. Impact assessment of traditional transport intensity - transport disruption on moderate or high intensity sections can lead to social consequences, which raises the risk of unpredictable disrupting the transportation process. Local authorities, due to the negative reaction of the population to the HOF transportation may refuse to issue permits to carry this type of freight through their territory, or to delay the permit delivery. In that case, the risk of increasing costs expands significantly. Time losses due to traffic intensity along the road route are evaluated according to the following formula:

$S_{A I}=x_{A I 1} \cdot k_{A I 1}+x_{A I 2} \cdot k_{A I 2}+x_{A I 3} \cdot k_{A I 3}$,

whereas: $S_{A I}$ - total costs of additional time during HOF transportation on the automobile road (in months); $x_{A I 1}$ - low intensity road section length on the route (in $\mathrm{km}$ ); $x_{A I 2}$ - moderate intensity road section length on the route (in $\mathrm{km}$ ); $x_{A I 3}$ - high intensity road section length on the route (in $\mathrm{km}$ ); $k_{A I 1}$ - size, evaluating the freight train speed on low intensity road section (in 
$1 / \mathrm{km} / \mathrm{h}$ ); $k_{A I 2}-$ size, evaluating the freight train speed on moderate intensity road section (in $1 /$ $\mathrm{km} / \mathrm{h}$ ); $k_{A B}-$ size, evaluating the freight train speed on high intensity road section (in $1 / \mathrm{km} / \mathrm{h}$ ). Barriers to legal requirements are calculated:

$$
K_{\text {legal }}=t_{L} \cdot d \text {, }
$$

whereas: $K_{\text {legal }}-$ criterion "Barriers to the numerical value of legal requirements $(\mathrm{SFV}) ; t_{L}-$ time for receipt of permission to transport in the territory (in months); $d$ - the amount of potential financial losses (losses).

10. Seasonality influence to the possibility of freight transportation - this criterion evaluates the seasonality of transport mode. Numeric value of factor depends on the time period during which it is possible to transport HOF. The influence of this criterion depends on the geographic area in which the freight transportation is planned and on the technical characteristics of the specific road. The weight of this criterion is the square dependence on the number of months per year when the freight is not transported. Numeric value of criterion is calculated by the following formula:

$$
K_{S E}=k_{\text {seas }} \cdot x_{s}^{2} \cdot d \text {, }
$$

whereas: $K_{S E}$ - numeric value of the "seasonality" criterion (in RFU); $k_{\text {seas }}-$ coefficient evaluating seasonality of the HOF transportation (according to multiannual experience in the Republic of Lithuania it is 0.5$) ; x_{s}$ - time period - number of months when HOF is not transported (in pcs.).

11. Existing experience in the transportation of $\mathrm{HOF}$ - this criterion evaluates existing experience for each mode of transport during HOF transportation. Regular HOF transportation during more than one year is considered as big experience. Experience for at least one or more freight transportation is considered as little experience. This criterion is also associated with the transportation risk assessment. The risk increases with the absence of experience in HOF transportation. It is very important to evaluate the existing experience of HOF carriers in this area.

$$
E_{i j} \in\left\{\begin{array}{l}
N, \quad N=[0 ; 3], \\
M, \quad M=[3 ; 20], \\
D, \quad D=\left[20, \ldots, n_{v}\right],
\end{array}\right.
$$

whereas: $E_{i j}$ - factor evaluating the existing experience in the HOF transportation agent by $i$-th mode of transport in $j$-th road section; $N$ - there is no experience in HOF transportation; $M$ there is a little experience in HOF transportation; $D$ - there is a big experience in HOF transportation; $n_{v}$ - number of cases concerning HOF transportation.

Transport risk appraisers typically are using the following classification of existing experience: no experience - when the carrier has performed no more than 3 HOF transportations; little experience - when the carrier has performed from 3 to $20 \mathrm{HOF}$ transportations; big experience - when the carrier has performed more than $20 \mathrm{HOF}$ transportations.

Number of carried equal freights - when it is necessary to deliver not a single HOF, but the greater lot as a group of freight related to a specific technology (oil refineries, wind powerplants etc.), it is appropriate to assess the number of identical freight, because it facilitates the organization of transportation.

\section{Discussion}

Hypothetical Lithuanian territory was chosen check the criteria system efficiency, where there is traditional road network of different modes of transport, natural geographic barriers restricting the possibilities of HOF transportation and specific economic-financial conditions (Figure 1). The task is to evaluate the options of HOF transportation, on this hypothetical territory, by selecting the most suitable route for HOF transportation when using the universal HOF routing and evaluation system, created and adapted for road transport.

A hypothetical task is formulated for system verification: distance of HOF transportation from point "A" to point "B" (between the points' geographical coordinates) is equal to 400 kilometres. It is possible to carry the HOF in three modes: by road, by rail and by inland water transport. Choosing the third HOF transportation alternative, there is no possibility to bring freight directly to the final destination 
(because there is no waterway to reach the final destination), so in order to use the inland waterway alternative it would require applying a multimodal (combined) transport option. Maximum HOF weight is 150 tons. Maximum HOF height is $6 \mathrm{~m}$, width $-5 \mathrm{~m}$, length $-15 \mathrm{~m}$. It is intended to carry HOF once on this route and there is no presumption that this route will be used many times.

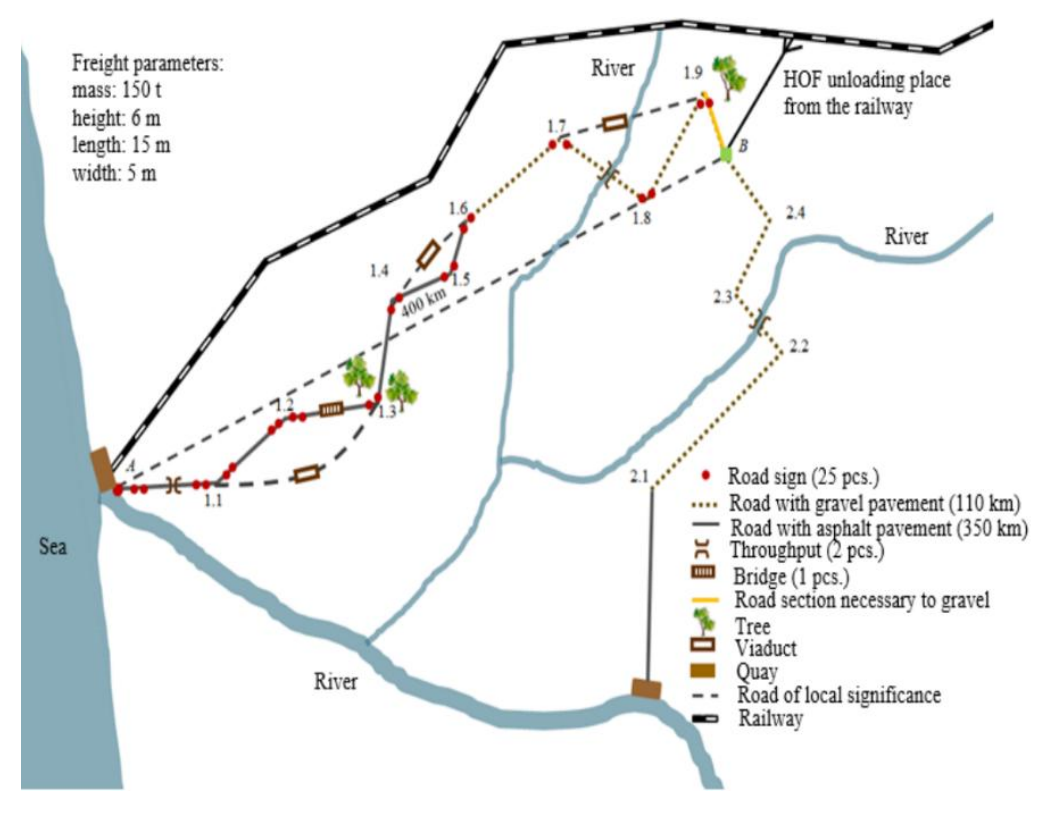

Figure 1. The scheme of hypothetic territory

On a hypothetical route, we will analyze the possibility of HOF transportation by road. Therefore, it is important to analyze and identify the critical points on the route that could restrict the HOF transportation (calculated based on road construction and rebuild prices in Lithuania). following:

After the analysis of freight transportation up to 150 tons on road transport, there is defined

- length of the road with asphalt pavement is $305 \mathrm{~km}$, length with a gravel pavement is $95 \mathrm{~km}$. the HOF is transported on asphalt pavement in average of $18 \mathrm{~km} / \mathrm{h}$, on gravel pavement $10 \mathrm{~km} / \mathrm{h}$;

- It is necessary to gravel 800 metres of road in a country, to dismantle 25 road signs, to disassemble 2 hedges on the route;

- it is necessary to widen 8 turnings on the route;

- it is necessary to remove the 3 trees providing the necessary freight corridor width (removal of trees is attributed to the minor works category);

- there are 3 viaducts on the route, which do not meet the parameters of freight transportation height, so it is necessary to bypass these viaducts;

- 2 throughputs and one 14 meter long bridge must be rebuilt on the route;

- the route passes through 15 villages;

- traffic intensity is high on $100 \mathrm{~km}$ route (it requires 6 hours to overcome this route), is average on $100 \mathrm{~km}$ route (it requires 6 hours to overcome this route), and is low on $200 \mathrm{~km}$ route (it requires 20 hours to overcome this route);

- it is possible to carry the HOF on the predicted route can carry 6 months per year.

The criteria weighting calculations on the road transport route:

- Whereas the use of existing road network is in the territory, the distance between point " $\mathrm{A}$ " and point " $\mathrm{B}$ " is not a straight line, so we get that HOF transportation will comprise 350 kilometres on the asphalt pavement and 110 kilometres on gravel pavement. Thus, the weight of criterion evaluating the road distance is calculated as follows (see Formulas 2, 3):

$$
k_{A D}=\frac{1}{b \cdot v_{\text {aver }}}=\frac{1}{720 \cdot 18}=0.00008 \text {; }
$$


$k_{A Z}=\frac{1}{b \cdot v_{\text {aver }}}=\frac{1}{720 \cdot 10}=0.0001$.

Total HOF transportation time by road on the route will be as follows (see Formula 1): $S_{A D}=x_{A 1} \cdot k_{A D}+x_{A 2} \cdot k_{A Z}=350 \cdot 0.00008+110 \cdot 0.0001=0.039$ (in months)

Increasing the route length, HOF transportation costs increases accordingly; the risk of negative transportation effects also increases. It is assumed that HOF transportation price for 1 $\mathrm{t} / \mathrm{km}$ is $500 \mathrm{RFU} / \mathrm{km}$. Therefore, estimating the influence of freight transportation distance, it is attributed a value of 500 units of the criterion weighting.

- Before starting to calculate the weight of criterion "road graveling", it is necessary to calculate the coefficient value $d$ of potential financial costs (losses) (see Formula 6). Assuming that the annual amount of credit for HOF transportation project implementation is 30 million RFU, and the bank's annual interest rate is $7.5 \%$. In such a case, it is considered that salary is included in the total amount of credit, but its changes do not affect the period of the credit use.

$d=\frac{E_{k} \cdot P_{b}}{12}=\frac{30000000 \cdot 0.075}{12}=187500(\mathrm{RFU})$.

Under specific conditions, after calculating the value of size $d$, the size $S_{A D}$ can be expressed in relative financial units (RFU):

$S_{A D}=0.039 \cdot 187500=73125(\mathrm{RFU})$.

$1 \mathrm{~km}$ of road graveling costs 205 thousand RFU, it takes in average one working week. Since it is necessary to graveling 800 meters of road, the value of the criterion is 8. Criterion "road graveling" is attributed to a minor works category and is equal to (see Formula 9):

$K_{\text {graveling }}=k_{g r v}+\left(t_{g r v} \cdot d\right)=20500+(0.023 \cdot 187500)=24813(\mathrm{RFU})$.

The average cost of destruction and rebuild of 100 metres of kerbs, road hedges or single road sign, taking all the costs of coordination with the necessary institutions, is $6000 \mathrm{RFU}$. This is attributable to the category of minor improvement works on the route.

- Increasing the radius of turning curvature corresponds to the construction of 100 metres of new road (cost of construction of 1 kilometre of asphalt local road is $\sim 897000$ RFU and designing time is $\sim 2$ months). The weighting value of criterion is calculated as follows:

$K_{n k}=k_{k}+\left(t_{s} \cdot d\right)=89700+(2 \cdot 187500)=464700(\mathrm{RFU})$.

- Taking into account the throughput designing and construction time (see Formula (12)) together with bypass road, financial expenses reach $\sim 3$ million RFU (throughput installation time is $\sim 2$ months, the time for receiving necessary permits is $\sim 2$ months).

$K_{t h}=k_{k}+\left(t_{c} \cdot d\right)+\left(l_{t h} \cdot a_{t h} \cdot k_{t h}\right)+\left(t_{t h} \cdot d\right)=$ $464700+6 \cdot 12 \cdot 25000+4 \cdot 187500=3014700(\mathrm{RFU})$.

Numeric value of criterion weight, evaluating the construction of new 14 meter long bridge is calculated as follows (see Formula 15):

$K_{T}=\left(l_{T} \cdot a_{T} \cdot k_{T}\right)+\left(t_{T} \cdot d\right)=14 \cdot 12 \cdot 27000+10 \cdot 187500=6411000(\mathrm{RFU})$.

Under current building regulations, the resistance limit for road bridges in hypothetical territory is 250 tons. Therefore, considering the impact of freight weight on the final result, it is assigned a weight value of new bridge construction criterion.

- To carry the HOF through the villages or towns, such transportation must be coordinated with the local authorities. Coordination takes approximately 1 month. The weighting value of criterion is calculated as follows:

$K_{\text {legal }}=t_{L} \cdot d=1 \cdot 187500=187500(\mathrm{RFU})$.

- Transporting HOF may encounter a regular disturbance in public life. The European Union has approved the methodology for assessment the latency of one man, moving by car, in public level [40]. This methodology is applied to motivate the investments in roads. According to this methodology, the criterion weight is calculated in high, medium and low traffic intensity road sections. Weighting of the criterion, considered under this methodology, is estimated by rate of 1 hour loss to the public (on low traffic intensity, losses comprise $606 \mathrm{RFU} / \mathrm{h}$, on average intensity - $4038 \mathrm{RFU} / \mathrm{h}$, on high traffic intensity - $9075 \mathrm{RFU} / \mathrm{h}$ ). 
- Seasonality criterion weight is equal to the seasonality coefficient multiplied by the size $d$ concerning financial costs (losses). The value of criterion concerning seasonality influence is calculated as follows (see Formula 24):

$$
K_{S E}=k_{\text {seas }} \cdot x_{s}^{2} \cdot d=0.5 \cdot 6^{2} \cdot 187500=3375000(\mathrm{RFU}) \text {. }
$$

Results of criterion evaluation concerning road transport route are shown in Table 1.

Table 1. Results of road transport criterion evaluation

\begin{tabular}{|c|c|c|c|c|}
\hline \multirow[b]{2}{*}{ No. } & \multirow[b]{2}{*}{ Criterion } & \multicolumn{3}{|c|}{ Road transport } \\
\hline & & $\begin{array}{l}\text { Criterion } \\
\text { value }\end{array}$ & $\begin{array}{l}\text { Criterion } \\
\text { weight }\end{array}$ & Result \\
\hline \multirow{5}{*}{1.} & $\begin{array}{l}\text { Influence of road section pavement to the freight transportation speed, } \\
S_{A D}\end{array}$ & & & 7312.5 \\
\hline & Physical quality of road pavement during assessment, $F_{A Q}$ & & & \\
\hline & Quality is appropriate & $x$ & $x$ & \\
\hline & Minor improvements & $\times$ & $\times$ & \\
\hline & Major works & 3 & 6411000 & 19233000 \\
\hline \multirow{4}{*}{2.} & Road turnings of small radius, $F_{A S}$ & & & \\
\hline & Radius of curvature meets requirement & $\times$ & 0 & \\
\hline & Minor improvements are necessary & 35 & 24813 & 868455 \\
\hline & Major works are necessary & 8 & 46400 & 371200 \\
\hline \multirow{10}{*}{3.} & Freight transportation corridor on the road section is too narrow, $F_{A K S}$ & & & \\
\hline & Corridor width is appropriate & $\times$ & $\times$ & \\
\hline & Minor improvements are necessary & 3 & 24813 & 74439 \\
\hline & Major works are necessary & $\times$ & $\times$ & \\
\hline & Rational solution of problem is impossible & $\times$ & $x$ & \\
\hline & Freight transportation corridor on the road section is too low, $F_{A K Z}$ & & & \\
\hline & Corridor height is appropriate & $\times$ & $x$ & \\
\hline & Minor improvements are necessary & $\times$ & $x$ & \\
\hline & Major works are necessary & $\times$ & $x$ & \\
\hline & Rational solution of problem is impossible & $\times$ & $x$ & \\
\hline \multirow{10}{*}{4.} & $\begin{array}{l}\text { Barriers due to bridges/dams on the route. Insufficient bridge carrying } \\
\text { capacity, } F_{A T}\end{array}$ & & & \\
\hline & $\begin{array}{l}\text { Bridge carrying capacity meets freight } \\
\text { transportation conditions }\end{array}$ & $x$ & $x$ & \\
\hline & Metal ramp is necessary & $\times$ & $\times$ & \\
\hline & Throughput should be installed & 2 & 3014700 & 6029400 \\
\hline & Construction of a new bridge/quay is necessary: & & & \\
\hline & Construction of bridge up to 42 m length & $\times$ & $x$ & \\
\hline & Construction of bridge up to $28 \mathrm{~m}$ length & $\times$ & $\times$ & \\
\hline & Construction of bridge up to $14 \mathrm{~m}$ length & 1 & 6411000 & 6411000 \\
\hline & Construction of bridge up to $42 \mathrm{~m}$ length & $x$ & $\begin{array}{ll}x \\
\end{array}$ & \\
\hline & Rational solution of problem is impossible & & & \\
\hline \multirow{5}{*}{5.} & Maximum weight of carried freight, $\boldsymbol{k}_{s v}$ & & & \\
\hline & Freight up to $100 \mathrm{t}$ & & $x$ & \\
\hline & Freight from $100 \mathrm{t}$ up to $250 \mathrm{t}$ & 1 & 6411000 & 6411000 \\
\hline & Freight from $250 \mathrm{t}$ up to $550 \mathrm{t}$ & $\times$ & $x$ & \\
\hline & Freight over $550 \mathrm{t}$ & $\times$ & $\times$ & \\
\hline 6. & Total length of route, $F_{\Sigma L}$ & 460 & 500 & 230000 \\
\hline \multirow{3}{*}{7.} & Demand for installation of transhipment sites, $F_{A P}$ & & & \\
\hline & No need for installation of transhipment site & $\times$ & $x$ & \\
\hline & Number of transhipment sites necessary to install & $\times$ & $x$ & \\
\hline \multirow{3}{*}{8.} & Demand for installation of freight storage areas (temporary), $F_{A Y}$ & & & \\
\hline & No need for installation of storage areas & $\times$ & $x$ & \\
\hline & Number of freight storage areas necessary to install & $\times$ & $x$ & \\
\hline \multirow{3}{*}{9.} & Obstacles due to the legal (including environmental) requirements, $F_{A J}$ & & & \\
\hline & $\begin{array}{l}\text { Demand for passage through towns/ villages (number of villages along the } \\
\text { route, distance through villages) }\end{array}$ & 15 & 187500 & 2812500 \\
\hline & demand for passage of protected areas & $\times$ & $x$ & \\
\hline \multirow{4}{*}{10.} & Traditional transport intensity on the analysed route, $S_{A I}$ & & & \\
\hline & Low & 6 & 606 & 3636 \\
\hline & Moderate & 6 & 4038 & 4044 \\
\hline & High & 20 & 9075 & 181500 \\
\hline \multirow[t]{2}{*}{11.} & $\begin{array}{l}\text { Seasonality influence to the possibility of freight transportation (in } \\
\text { months per year), } K_{S E}\end{array}$ & $6^{2}$ & 93750 & 3375000 \\
\hline & \multicolumn{4}{|l|}{ 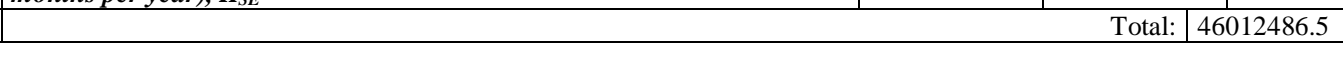 } \\
\hline
\end{tabular}

Note: $\times$ - in this case criterion practically has no influence. 


\section{Conclusions}

In scientific literature is a lack of methodology concerning the performance of calculations and choice of elements, what must be assessed, during HOF transportation. In most cases, scientists consider only individual items or groups: for example, influence of HOF transportation to the road pavement; various structures and buildings along the transportation section etc.

In this article was formulated a set of 11 criteria with individual sub criteria, that defines HOF transportation processes, evaluates parameters of the route, the type of transportation and transportation vehicles. This allows to assess in a common system all the HOF transportation processes applying the comparative method.

HOF routes and processes evaluation criteria can be grouped into two groups, in one group all criteria have the time dimension, and in another - the monetary dimension. This allows the formation of the evaluation system ensuring an objective assessment of the HOF transportation processes by comparing different types of transportation, route segments, technologies of transportation and freight transhipment.

\section{References}

1. Abulizi, N., Kawamura, A., Tomiyama, K., Fujita, S. (2016) Measuring and evaluating of road roughness conditions with a compact road profiler and ArcGIS. Journal of Traffic and Transportation Engineering, 3(5), 398-411. doi:10.1016/j.jtte.2016.09.004

2. Andrés, L., Padilla, E. (2015) Energy intensity in road freight transport of heavy goods vehicles in Spain. Energy Policy, 85, 309-321. doi:10.1016/j.enpol.2015.06.018

3. Armstrong, M., Taylor, J. Regional Economics and Policy. Wiley-Blackwell; 2000. 448 p.

4. Bartuška, L., Biba, V., Jeřábek, K. (2016) Verification of methodical procedure for determining the traffic volumes using short-term traffic surveys. Procedia Engineering, 161, 275-281. doi:10.1016/j.proeng.2016.08.553

5. Bazaras, D., Batarlienè, B., Palšaitis, R., Petraška, A. (2013) Optimal road route selection criteria system for oversize goods transportation. The Baltic Journal of Road and Bridge Engineering, 8(1), 19-24. doi:10.3846/bjrbe.2013.03

6. Benekos, I., Diamantidis, D. (2017) On risk assessment and risk acceptance of dangerous goods transportation through road tunnels in Greece. Safety Science, 91, 1-10. doi:10.1016/j.ssci.2016.07.013

7. Bickel, P., Friedrich, R., Burgess, A., Fagiani, P., Hunt, A., De Jong, G., Laird, J., Lieb, C., Lindberg, G., Mackie, P., Navrud, S., Odgaard, T., Ricci, A., Shires, J., Tavasszy, L. (2006) HEATCO: Developing Harmonised European Approaches for Transport Costing and Project Assessment. Contract No. FP6-2002-SSP-1/502481. IER, Germany, from http://heatco.ier.unistuttgart.de/HEATCO_D5.pdf

8. Bula, G.A., Prodhon, C., Gonzalez, F.A., Afsar, H.M.;Velasco, N. (2017) Variable neighborhood search to solve the vehicle routing problem for hazardous materials transportation. Journal of Hazardous Materials, 324(Part B), 472-480. doi:10.1016/j.jhazmat.2016.11.015

9. Carrara, S., Longden, T. (2017) Freight futures: The potential impact of road freight on climate policy. Transportation Research Part D: Transport and Environment, 55, 359-372. doi:10.1016/j.trd.2016.10.007

10. Conca, A., Ridella, C., Sapori, E. (2016) A risk assessment for road transportation of dangerous goods: A routing solution. Transportation Research Procedia, 14, 2890-2899. doi:10.1016/j.trpro.2016.05.407

11. Datla, S.K., Moorthy, R.S., Krishna Rao, K.V. (2004) A GIS for routing of oversized and hazardous material carrying vehicles. Map Asia Conference 2004, Beijing, China, 26-29 August 2004, 1-14.

12. Dell'Acqua, G., De Luca, M., Prato, C.G., Prentkovskis, O., Junevičius, R. (2016) The impact of vehicle movement on exploitation parameters of roads and runways: a short review of the special issue. Transport, 31(2), 127-132. doi:10.3846/16484142.2016.1201912

13. Doumiati, M., Erhart, S., Martinez, J., Sename, O., Dugard, L. (2014) Adaptive control scheme for road profile estimation: application to vehicle dynamics. IFAC Proceedings Volumes, 47(3), 84458450 .

14. Durham, G., Faghri, A. (2002) GIS Application for Oversize Vehicle Routing through a Virtual Road and Bridge Network. University of Delaware, National Science Foundation, Research Experiences for Undergraduates in Bridge Engineering, USA. 29 p. 
15. ECMT. (2006) Improving Transport Accessibility for All: Guide to Good Practice. European Conference of Ministers of Transport (ECMT). OECD publications service. $161 \mathrm{p}$., from https://www.itf-oecd.org/sites/default/files/docs/06tphguide.pdf

16. El-Rashidy, R.A., Grant-Muller, S. (2016) The evaluation of redundancy for road traffic networks. Transport, 31(4), 427-439. doi:10.3846/16484142.2016.1255913

17. Gardziejczyk, W., Zabicki, P. (2017) Normalization and variant assessment methods in selection of road alignment variants - case study. Journal of Civil Engineering and Management, 23(4), 510523. doi:10.3846/13923730.2016.1210223

18. Hall, J.W., Sullivan, E.C., Reilly, W.R., Homburger W.S. (2007) Fundamentals of Traffic Engineering. University of California. 464 p.

19. Iwański, M., Buczyński, P., Mazurek, G. (2016) Optimization of the road binder used in the base layer in the road construction. Construction and Building Materials, 125, 1044-1054. doi:10.1016/j.conbuildmat.2016.08.112

20. Kombe, T., Ele, P., Offole, F., Miasse, H. O. (2017) Modelling an interactive road signs system, using Petri nets. Transport and Telecommunication Journal, 18(1), 34-44. doi:10.1515/ttj-20170004

21. Li, X.-H., Han, Y.-H., Tan, Y.-L. (2014) Analysis of the effect of heavy duty freight cars loaded overweight goods on the track structure. Procedia - Social and Behavioral Sciences, 138, 45-53. doi:10.1016/j.sbspro.2014.07.180

22. Newnam, S., Goode, N., Salmon, P., Stevenson, M. (2017) Reforming the road freight transportation system using systems thinking: An investigation of Coronial inquests in Australia. Accident Analysis \& Prevention, 101, 28-36. doi:10.1016/j.aap.2017.01.016

23. Palšaitis, R., Petraška, A. (2012) Heavyweight and oversized cargo transportation risk management. Transport and Telecommunication, 13(1), 51-56. doi:10.2478/v10244-012-0005-9

24. Park, S.W. (2004) Modelling of deformational characteristics in unbound granular geomaterials. KSCE Journal of Civil Engineering, 8(3), 281-285. doi:10.1007/BF02836010

25. Pauer, G. (2017) Development potentials and strategic objectives of intelligent transport systems improving road. Transport and Telecommunication Journal, 18(1), 15-24. doi:10.1515/ttj-20170002

26. Petraška, A., Čižiūnienè, K., Jarašūnienè, A., Maruschak, P., Prentkovskis, O. (2017) Algorithm for the assessment of heavyweight and oversize cargo transportation routes. Journal of Business Economics and Management, 18(6), 1098-1114. doi:10.3846/16111699.2017.1334229

27. Petraška, A., Palšaitis, R. (2012) Evaluation criteria and a route selection system for transportating oversize and heavyweight cargoes. Transport, 27(3), 327-334. doi.org: 10.3846/16484142.2012.721133

28. Podvezko V., Sivilevičius, H. (2013) The use of AHP and rank correlation methods for determining the significance of the interaction between the elements of a transport system having a strong influence on traffic safety. Transport, 28(4), 389-403. doi:10.3846/16484142.2013.866980

29. Pronello, C., Camusso, C., Valentina, R. (2017) Last mile freight distribution and transport operators' needs: which targets and challenges? Transportation Research Procedia, 25, 888-899. doi:10.1016/j.trpro.2017.05.464

30. Sánchez-Díaz, I. (2017) Modeling urban freight generation: A study of commercial establishments' freight needs. Transportation Research Part A: Policy and Practice, 102, 3-17. doi:10.1016/j.tra.2016.06.035

31. Sarker, B.R., Baylot, E.A., Green, J.G., Biswas, P. (2012) Convoy movement: consideration of turning geometrics for selected vehicle shapes. Journal of Transportation Engineering, 138(5). doi:10.1061/(ASCE)TE.1943-5436.0000359

32. Sivilevičius, H. (2011) Modelling the interaction of transport system elements. Transport, 26(1), 20-34. doi:10.3846/16484142.2011.560366

33. Sivilevičius, H., Šukevičius, Š. (2007) Dynamics of vehicle loads on the asphalt pavement of european roads which cross Lithuania. The Baltic Journal of Road and Bridge Engineering, 2(4), 147-154.

34. Sivilevičius, H., Vislavičius, K., Bražiūnas, J. (2017) Technological and economic design of asphalt mixture composition based on optimization methods. Journal of Civil Engineering and Management, 23(4), 627-648. doi:10.3846/13923730.2016.1210223

35. Sousa, H., Costa, B.J.A., Henriques, A.A., Bento, J., Figueiras, J.A. (2016) Assessment of traffic load events and structural effects on road bridges based on strain measurements. Journal of Civil Engineering and Management, 22(4), 457-469. doi:10.3846/13923730.2014.897991 
36. Ušpalytė-Vitkūnienė, R., Laureshyn, A. (2017) Perspectives for surrogate safety studies in EastEuropean countries. The Baltic Journal of Road and Bridge Engineering, 12(3), 161-166. doi:10.3846/bjrbe.2017.19

37. Vaitkus, A.,Strumskys, M., Jasiūnienė, V., Jateikienė, L., Andriejauskas, T., Skrodenis, D. (2016) Effect of intelligent transport systems on traffic safety. The Baltic Journal of Road and Bridge Engineering, 11(2), 136-143. doi:10.3846/bjrbe.2016.16

38. Van Damme, O., Van Geelen, H., Courange, P. (2016) The Evaluation of Road Infrastructure Development Projects. Transportation Research Procedia, 14, 467-473. doi:10.1016/j.trpro.2016.05.099

39. Wang, K.C.P., Li, Q., Hall, K.D., Nguyen, V., Xiao, D.X. (2011) Development of truck loading groups for the mechanistic-empirical pavement design guide. Journal of Transportation Engineering, 137(12). doi:10.1061/(ASCE)TE.1943-5436.0000277

40. Xu, C., Hoel, L.A. (2001) A Methodology for Oversized Vehicle Trip Scheduling. Research Report No. UVACTS-14-13-23. Center for Transportation Studies, University of Virginia, USA, 85 p. 